\title{
The Effect of Corticosteroids on Orthodontic Tooth Movement - A Review
}

\author{
Alok Kumar \\ Assistant Professor, Department Of Orthodontics \&Dentofacial Orthopaedics, Awadh Dental College \\ \&Hospital, Jamshedpur, India
}

\begin{abstract}
Greater awareness about the benefits of orthodontic treatment and increasing life expectancy is encouraging an increasing number of adult patients to seek orthodontic treatment. This presents new opportunities for the speciality of Orthodontics. But along with the opportunities there are also a new set of challenges. Adult patients are more likely to suffer from systemic diseases and consequently there is an increased likelihood that they would be under various kinds of medications. A group of drugs which is widely used for treating and ameliorating the pain and suffering of millions around the world today is Corticosteroids. It has been established that corticosteroids possess potent anti-inflammatory and immunemodulating properties. It has also been shown to have an effect on orthodontic tooth movement. This paper attempts to understand the mechanism of action of corticosteroid and its effects on the process of orthodontic tooth movement based on available scientific data and research.
\end{abstract}

Keywords: Corticosteroids, Orthodontic tooth movement.

\section{Introduction}

It was the year 1929 when Charles $\mathrm{H}$ Tweed facilitated passing of the - first orthodontic speciality law in United States, limiting the practice of orthodontics to specialists. Of course it was at the behest of his guide and mentor, Edward Hartley Angle, today considered as the father of modern orthodontics. ${ }^{1}$ Since then the speciality of Orthodontics has seen tremendous refinements in both materials as well as techniques used to bring about desired tooth movement. The changes incorporated in the speciality have been so profound that the treatment, which till a few decades back, was considered appropriate only for children \& adolescent, is seeing more and more adults seeking its benefits. However this new opportunity has also brought with itself a new set of challenges for the speciality. ${ }^{2-4}$

An adult Orthodontic patients is more likely to be affected by systemic diseases that need medical treatment with drugs that could possibly affect bone metabolism. ${ }^{5}$ Corticosteroids happen to be one such group of drugs which since their identification nearly 80 years ago, have played a prominent role in the treatment of many diseases afflicting mankind. Today, many of the clinical roles of steroids are related to their potent antiinflammatory and immune-modulating properties. ${ }^{6}$ Some of the more common medical conditions in which chronic oral glucocorticoid use is recommended to patients are rheumatoid arthritis, chronic obstructive pulmonary disease, systemic lupus erythematosus, inflammatory bowel disease, asthma, dermatitis \& eczema. Many of these diseases have high incidences and rapidly increasing prevalence. ${ }^{7-8}$ Therefore it is logical to conclude that the number of such patients seeking orthodontic care is going to increase in the near future.

In spite of its usefulness the clinically relevant side effects of steroids are common and problematic, ranging from a minor case of acne to Cushing syndrome that can result in diabetes mellitus and potentially lifethreatening heart disease if untreated..$^{9}$ One of the more common and serious side effect of chronic steroid use is pathological fracture. ${ }^{7}$ Glucocorticoids affect bone mineralization by inhibiting calcium absorption in the gastrointestinal tract and shifting signalling-molecule production to favour bone resorption. ${ }^{10}$ Studies have also shown that corticosteroids affect orthodontic tooth movement. ${ }^{11-12}$

This review paper attempts to understand the mechanism of action of corticosteroid and its effects on the process of orthodontic tooth movement based on available scientific data and research.

\section{Understanding Orthodontic Tooth Movement}

A tooth can be moved through the alveolar bone when an appropriate orthodontic force is applied. This is based on the principle that a change in mechanical loading of a biological system results in strain, which subsequently leads to cellular responses aiming at adaptation of the system to the changed conditions. As a result of this principle, remodelling of the periodontal ligament (PDL) and the alveolar bone around a tooth takes place during orthodontic force application. ${ }^{13}$ This movement is mediated by coupling bone resorption and deposition in compressed and stretched sides of the PDL, respectively. Orthodontic forces, by virtue of altering the blood flow and localized electrochemical environment, upset the homeostatic environment of the PDL 
space. This abrupt alteration initiates biochemical and cellular events that reshape the bony contour of the alveolus. $^{14}$

The biologic foundation of force-induced tooth movement, along with the various concepts related to it, has been extensively investigated. This has led to the proposal of two main mechanisms for tooth movementthe application of pressure and tension to the PDL, and bending of the alveolar bone. ${ }^{15}$

Research about tooth movement by Sandstedt (1904), Oppenheim (1911), and Schwarz (1932) led them to hypothesize that a tooth moves in the periodontal space by generating a - pressure side and a - tension side. ${ }^{16-18}$ This hypothesis explained that, on the pressure side, the PDL displays disorganization and diminution of fibre production. Here, cell replication decreases seemingly due to vascular constriction. On the tension side, stimulation produced by stretching of PDL fibre bundles results in an increase in cell replication. This enhanced proliferative activity leads eventually to an increase in fibre production. ${ }^{19}$

Baumrind proposed an alternative hypothesis in 1969, known as the bone-bending theory. It states that orthodontic forces routinely produce alveolar bone deflection, and that these strains are accompanied by changes in the PDL. Farrar was the first to suggest, in 1888, that alveolar bone bending plays a pivotal role in orthodontic tooth movement. This hypothesis was later confirmed with the experiments of Baumrind in rats and Grimm in humans. According to these authors, when an orthodontic appliance is activated, forces delivered to the tooth are transmitted to all tissues near force application. These forces bend bone, tooth, and the solid structures of the PDL. Bone was found to be more elastic than the other tissues and was likely to bend far more readily in response to force application. The active biologic processes that follow bone bending involve bone turnover and renewal of cellular and inorganic fractions. These processes are accelerated while the bone is held in the deformed position. ${ }^{19-21}$

However neither hypothesis provides conclusive evidence on the detailed nature of the biologic mechanism of tooth movement. Many phenomena, both physical and biologic, are involved in tooth movement. When mechanical forces are applied, cells, as well as the extracellular matrix of the PDL and alveolar bone, respond concomitantly, resulting in tissue remodelling. During early phases of tooth movement, PDL fluids are shifted, producing cell and matrix distortions, as well as interactions between these tissue elements. In response to these physicochemical events and interactions, cytokines, growth factors, colony-stimulating factors, and vasoactive neurotransmitters are released, initiating and sustaining the remodelling activity, which facilitates tooth movement ${ }^{15,22}$

After an orthodontic force is applied, the initial step is the detection of a mechanical strain. The cells responsible for sensing mechanical strains in bone have been considered to be osteoblasts, osteocytes, or both. Theories on how these cells sense strain in their environment include streaming potentials, strain-sensitive ion channels and cytoskeletal reorganization. ${ }^{23}$

Arachidonic (eicosatetraenoic) acid, the main component of phospholipids of the cell membrane, is released due to the action of phospholipase enzymes. The released acid can be metabolized by 2 pathways - the cyclooxygenase pathway (with the help of cyclooxygenase enzymes producing prostaglandins and thromboxanes) and the lipooxygenase pathway leading to release of leukotriens and hydroxyeicosatetraenoic acids. The evidence for the involvement of these eicosanoids in the bone remodelling process incident to orthodontic tooth movement has been extensively published. ${ }^{24}$

The production of mediators by bone and PDL cells during mechanical stimulation indicates that these cells become activated. Precursors in the PDL are stimulated to differentiate into osteoblasts through factors produced by activated osteocytes. ${ }^{25}$ Examples of these factors are bone morphogenic proteins $(2,6$, and 9) and platelet-derived growth factor that also stimulate osteoblast activity. ${ }^{26-27}$ Osteocytes also respond to strain by the production of cytokines, $\mathrm{NO}$, prostaglandins, and tumour necrosis factor- $\alpha^{28}$

At the resorption site, soluble factors such as colony-stimulating factor, receptor activator of nuclear factor kappa $\beta$ ligand (RANKL), osteoprotegerin, and bone morphogenic proteins regulate osteoclast differentiation. ${ }^{29-30}$ These factors are produced by osteocytes present in the alveolar bone and by osteoblasts and fibroblast present in the PDL. ${ }^{31}$

Bone formation at the apposition side of the tooth is a combination of extra cellular matrix (ECM) synthesis and mineralization. Studies show that loading of PDL cells results in an increased production of alkaline phosphatase, osteocalcin, and other non-collagenous matrix proteins. ${ }^{32-33}$ These factors might stimulate precursors in the PDL to differentiate into osteoblasts, leading to subsequent bone deposition. Several mediators produced by activated PDL and bone cells stimulate ECM synthesis and reduce its degradation. Examples are members of the transforming growth factor- $\beta$ (TGF- $\beta$ ) superfamily. ${ }^{34}$ Increased levels of transforming growth factor- $\beta$, cathepsins $\mathrm{B}$ and $\mathrm{L}$, and interleukin-1 beta have also been found in the crevicular fluid of orthodontically moved teeth in humans and at the apposition side of rat teeth after orthodontic force application. $^{35}$

Therefore fibroblasts, osteoblasts, osteocytes, and osteoclasts are part of a complex regulatory network that induces PDL and bone remodelling during orthodontic tooth movement. 


\section{Mechanism of Action of Corticosteroids}

Since their identification in 1935, steroids have served in wide range of uses. The term steroid applies to a wide range of molecules with varying physiological effects. More specifically, corticosteroids are a class of chemicals encompassing both laboratory-synthesized and naturally produced hormones. Glucocorticoids, in general, regulate metabolism and inflammation; mineralocorticoids regulate sodium and water levels. ${ }^{6}$

The anti-inflammatory properties of steroids have been attributed to their inhibitory effects on the action of phospholipase A2, an enzyme critical to the production of inflammatory compounds. ${ }^{36}$ Research has shown that steroids are active in affecting gene expression, translation, and enzyme activity. ${ }^{37}$

Based on recent developments in understanding the fundamental mechanisms of gene transcription and cell signaling in inflammation there have been important advances in understanding the molecular mechanisms whereby corticosteroids suppress inflammation so effectively. ${ }^{37}$ Chronic inflammatory diseases, involve the infiltration and activation of many inflammatory and immune cells, which release multiple inflammatory mediators that interact and activate structural cells at the site of inflammation. The pattern of inflammation clearly differs between diseases, with the involvement of many different cells and mediators, but all are characterized by increased expression of multiple inflammatory proteins. ${ }^{38}$

The increased expression of most of these inflammatory proteins is regulated at the level of gene transcription through the activation of pro-inflammatory transcription factors, such as nuclear factor- $\mathrm{KB}$ (NF- $\mathrm{KB}$ ) and activator protein-1 (AP-1). These pro-inflammatory transcription factors are activated in all inflammatory diseases and play a critical role in amplifying and perpetuating the inflammatory process. ${ }^{39}$

Corticosteroids diffuse readily across cell membranes and bind to glucocorticoid receptors (GR) in the cytoplasm. Cytoplasmic GR are normally bound to proteins, known as molecular chaperones, that protect the receptor and prevent its nuclear localization by covering the sites on the receptor that are needed for transport across the nuclear membrane into the nucleus. ${ }^{40}$

Once corticosteroids have bound to GR, changes in the receptor structure result in dissociation of molecular chaperone proteins, thereby exposing nuclear localization signals on GR. This results in rapid transport of the activated GR-corticosteroid complex into the nucleus, where it binds to DNA at specific sequences in the promoter region of corticosteroid-responsive genes known as glucocorticoid response elements (GRE). Two GR molecules bind together as a homodimer and bind to GRE, leading to changes in gene transcription. Interaction of GR with GRE classically leads to an increase in gene transcription (transactivation). ${ }^{41}$

Corticosteroids produce their effect on responsive cells by activating GR to directly or indirectly regulate the transcription of target genes.GR homodimers bind to GRE sites in the promoter region of corticosteroid-responsive genes. Interaction of the activated GR dimer with GRE usually increases transcription. The activation of genes by corticosteroids is associated with a selective acetylation of lysine residues 5 and 16 on histone $\mathrm{H} 4$, resulting in increased gene transcription. ${ }^{42}$

Several of the genes that are switched on by corticosteroids have anti-inflammatory effects, including annexin-1 (lipocortin-1), interleukin-10 (IL-10) and the inhibitor of NF- $k \mathrm{~B}$ (I $\kappa \mathrm{B}-\alpha){ }^{43}$ Corticosteroids also switch on the synthesis of protein that affect inflammatory signal transduction pathways, glucocorticoid-induced leucine zipper protein (GILZ), which inhibits both NF- $k \mathrm{~B}$ and AP- $1 .{ }^{44}$

Although most of the actions of corticosteroids are mediated by changes in transcription through chromatin remodeling, it is increasingly recognized that they may also affect protein synthesis by reducing the stability of mRNA so that less protein is synthesized. It is increasingly recognized that several inflammatory proteins are regulated post-transcriptionally at the level of mRNA stability. This may be an important antiinflammatory mechanism as it allows corticosteroids to switch off the ongoing production of inflammatory proteins after the inflammatory gene has been activated. ${ }^{45}$

Inflammatory genes, such as the genes encoding cyclooxygenase-2 (COX2), produce mRNA that is particularly susceptible to the action of ribonucleases that break down mRNA, thus switching off protein synthesis. Corticosteroids may have inhibitory effects on the proteins that stabilize mRNA, leading to more rapid breakdown and thus a reduction in inflammatory protein expression. ${ }^{46-47}$

To conclude it would be appropriate to say that the predominant effect of corticosteroids is to switch off multiple inflammatory genes (encoding cytokines, chemokines, adhesion molecules, inflammatory enzymes, receptors and proteins) that get activated during the inflammatory pathway.

\section{The Effects of Corticosteroids on Orthodontic Tooth Movement}

The prevalence of pathological processes treated by corticosteroids is widespread in the medical and dental practice, and the response of patients undergoing orthodontic treatment may differ from normal bone remodelling due to the use of these drugs. ${ }^{48}$ It has been shown that orthodontic tooth movement can be affected by local or general administration of pharmacological agents. ${ }^{48-49}$ However there are only a limited number of 
studies which have been conducted to understand the effect of corticosteroid on bone tissue and orthodontic tooth movement.

In 1992 an in-vivo study on white New Zealand rabbits was conducted to find out the effects of corticosteroid induced osteoporosis on orthodontic tooth movement. The researchers concluded that rabbits subjected to corticosteroid-induced osteoporosis undergo significantly more rapid orthodontic tooth movement and subsequent relapse than control animals. ${ }^{50}$

In 1997 an in vitro study carried out to measure orthodontic tooth movement in rats given betaaminopropionitrile (BAPN) or hydrocortisone using a time-lapse videotape recorder concluded that treatment with BAPN accelerated experimental tooth movements in vitro and hydrocortisone treatment inhibited the movements. $^{49}$

Another study carried out on rats in 2000 , concluded that while there were no significant differences in the magnitude of tooth movement between the groups, steroid-treated rats displayed significantly less root resorption on the compression side and fewer TRAP (tartrate-resistant acid phosphatase) positive cells within the PDL(periodontal ligament) space on the same side. Thus they proposed that steroid treatment suppressed clastic activity. ${ }^{12}$

In a study in 2004, tissue reaction to orthodontic tooth movement in acute and chronic corticosteroid treatment was carried out and it was found that tooth movement rate increased in the chronic group. Force application resulted in significant increase in the relative extension of resorption and formation in both drug groups. It was particularly pronounced in the chronic group.The authors suggested that since acute corticosteroid ingestion reduces bone turnover, in these patients orthodontic treatment might best be postponed until a time the patient is free of the drug. It was said that chronic steroid ingestion leads to an increased biological reaction to mechanical perturbation indicating that the orthodontic force level should be reduced and controlled more frequently in patients on chronic steroid treatment. ${ }^{48}$

In another study conducted in 2006, to investigate the effect of acute and chronic corticosteroid treatment on orthodontically induced root resorption it was found that the acute group showed significantly more root resorption at the mesio-coronal level compared with the control and the chronic group. The researchers ascribed it to the lack of balance between blastic activities (inhibited by the drug) and the clastic activities (enhanced or unchanged by drug administration) occurring in the initial phase of drug administration. They also recommended careful monitoring of patients undergoing acute corticosteroid treatment. ${ }^{51}$

In 2009, a study was conducted to study the effects of steroidal and non-steroidal drugs on tooth movement and root resorption in the rat molar. The authors concluded that only prednisolone- and high-dose celecoxib-treated groups showed significantly less root resorption and less tooth movement. Administration of prednisolone and high-dose celecoxib reduced root resorption and interfered with tooth movement in rats. They proposed that the drugs may interfere in the arachidonic acid cascade depending on dose thresholds. ${ }^{52}$

A study in 2012 tried to investigate the effect of different courses of glucocorticosteroid treatment on orthodontic tooth movement (OTM). The researcher found higher rate of OTM in steroid treated groups than control group. Among steroid treated groups short-course group showed higher rate of OTM compared to longcourse group. The study recommended postponing, wherever possible, orthodontic treatment till the acute phase of treatment with corticosteroid is over. ${ }^{53}$

In 2014 a study was carried out to evaluate the effects of triamcinolone acetonide injection on orthodontic tooth movement in a rabbit model. It was found that treatment with triamcinolone acetonide was associated with increased tooth movement in rabbits via increased resorptive activity in the alveolar bone. ${ }^{54}$

After reviewing the existing literature on effects of corticosteroid on orthodontic tooth movement, it would not be wrong to conclude that, the results obtained so far are inconsistent and at times contradictory. It is also important to acknowledge the lack of any standardized protocol for research on the topic. This may have had an important bearing on the results obtained so far. Perusing the methodology of the above studies on can clearly observe that there are too many variables at play. The dosage, duration and rout of drug administration, magnitude of force applied to bring about tooth movement etc. Therefore there is a pressing need for further studies (preferably human studies) on the topic.

\section{Conclusion}

Ever since its discovery, the Corticosteroid group of drugs have helped in treating and ameliorating the pain and sufferings of millions around the world. However it also has the potential to cause serious side effects. One of the side effects which is of concern for orthodontists, around the world, is its capacity to affect bone physiology\& remodelling and by doing so affecting the rate of orthodontic tooth movement (OTM). Upon reviewing the existing literature on the topic it can be concluded that -

1. Corticosteroids group of drugs affect the rate of orthodontic tooth movement and may also affect the long term stability of orthodontically moved teeth. 
2. It is imperative to take a thorough medical and drug intake history of all patients, young and old alike, so as to formulate an appropriate treatment plan.

3. Orthodontic patients undergoing concomitant steroid therapy should be subjected to periodic clinical and radiographic examination to assess the patients response to treatment and modulations required in treatment mechanics during the course of treatment.

4. There is a pressing need for further research, preferably on human subjects, for a better understanding of the phenomenon.

\section{References}

[1]. Lee W Graber, Robert L Vanarsdall, Katherine W L Vig and Greg J Huang; Orthodontics: Current Principles and Techniques; 6th Edition; Elsevier: 2016; p482-483

[2]. Sona Pabari , David R. Moles, Susan J. Cunningham; Assessment of motivation and psychological characteristics of adult orthodontic patients; AJODO; December 2011,Volume 140, Issue 6, Pages e263-e272

[3]. Sumathi Reddy; Why More Adults Are Getting Braces: The Wall Street Journal; Weblog. Available form: http://www.wsj.com/articles/why-more-adults-are-getting-braces-1444066342 (Accessed 04 July 2016)

[4]. L. Christensen \& F. Luther; Adults seeking orthodontic treatment: expectations, periodontal and TMD issues; British Dental Journal $218,111-117(2015)$

[5]. Verna C, Dalstra M, Melsen B. The rate and the type of orthodontic tooth movement is influenced by bone turnover in a rat model. Eur J Orthod. 2000 Aug; 22 (4): 343-52

[6]. William Ericson-Neilsen and Alan David Kaye; Steroids: Pharmacology, Complications, and Practice Delivery Issues; Ochsner J. 2014 Summer; 14(2): 203-207

[7]. Curtis JR, Westfall AO, Allison J, et al. Population-based assessment of adverse events associated with long-term glucocorticoid use. Arthritis Rheum. 2006 Jun 15;55(3):420-426

[8]. Angeli A, Dovio A, Sartori M, Masera RG, Ceoloni B, Prolo P, Racca S, Chiappelli F. Interactions between glucocorticoids and cytokines in the bone microenvironment Ann N Y Acad Sci. 2002 Jun; 966: 97-107.

[9]. Stewart PM, Krone NP. The adrenal cortex. In: Melmed S, Polonsky K, Larsen PR, Kronenberg H, editors. Williams Textbook of Endocrinology. 12th ed. Philadelphia, PA: Saunders; 2011. In. eds.

[10]. Pereira RM, Carvalho JF, Canalis E. Glucocorticoid-induced osteoporosis in rheumatic diseases. Clinics (Sao Paulo) 2010;65(11):1197-1205.

[11]. Theodosia Bartzela, Jens C. Türp, Edith Motschall, and Jaap C. Maltha; Medication effects on the rate of orthodontic tooth movement: A systematic literature review; American Journal of Orthodontics and Dentofacial Orthopedics; 2009 Jan; Volume 135, Number $1 ; 16-26$

[12]. Ong CK, Walsh LJ, Harbrow D, Taverne AA, Symons AL. Orthodontic Tooth Movement in the Prednisolone-Treated Rat; Angle Orthodontist, Vol 70, No 2, 2000: 118-125

[13]. S. Henneman , J. W. Von den Hoff and J. C. Maltha ; Mechanobiology of tooth movement, European Journal of Orthodontics;2008 Jun:30(3): 299-306.

[14]. Toms SR, Lemons JE, Bartolucci AA, Eberhardt AW. Nonlinear stress-strain behavior of periodontal ligament under orthodontic loading. Am J Orthod Dentofacial Orthop 2002;122:174-9

[15]. Vinod Krishnana and Ze'ev Davidovitchb; Cellular, molecular, and tissue-level reactions to orthodontic force; American Journal of Orthodontics and Dentofacial Orthopedics. April 2006;2006; $129: 469$. e1 - 469.e32

[16]. Sandstedt C. Einige beiträge zur theorie der zahnregulierung. Nord Tandlaeg Tidskr 1904;5:236-56.

[17]. Oppenheim A. Tissue changes, particularly of the bone, incident to tooth movement. Am Orthod 1911;3:57-67

[18]. Schwarz AM. Tissue changes incident to orthodontic tooth movement. Int J Orthod 1932;18:331-52

[19]. Baumrind S. A reconsideration of the property of the pressure tension hypothesis. Am J Orthod 1969;55:12-22

[20]. Farrar JN. Irregularities of the teeth and their correction. Vol 1. New York: DeVinne Press; 1888. p. 658

[21]. Grimm FM. Bone bending, a feature of orthodontic tooth movement. Am J Orthod 1972;62:384-93

[22]. Davidovitch Z. Tooth movement. Crit Rev Oral Biol Med 1991;2:411-50

[23]. Calogero Dolce, J. Scott Malone, and Timothy T. Wheeler; Current Concepts in the Biology of Orthodontic Tooth Movement; Seminars in Orthodontics, Vol 8, No 1 (March), 2002: pp 6-12

[24]. Sandy JR, Meikle MC. Recent advances in understanding mechanically induced bone remodeling and their relevance to orthodontic therapy and practice. Am J Orthod Dentofacial Orthop 1993;103:212-22

[25]. Dereka X E, Markopoulou C E, Vrotsos I A; 2006; Role of growth factors on periodontal repair: Growth Factors: 2006 Dec: 24(4) $: 260-267$

[26]. Cheng $\mathrm{H}$ et al. Osteogenic activity of the fourteen types of human bone morphogenetic proteins (BMPs). Journal of Bone and Joint Surgery: 2003 Aug: $85 \mathrm{~A}(8), 1544-1552$

[27]. Singhatanadgit W, Salih V, Olsen I;Up-regulation of bone morphogenetic protein receptor IB by growth factors enhances BMP-2induced human bone cell functions . Journal of Cellular Physiology; 2006 Dec; 209(3) : 912 - 922

[28]. Klein-Nulend J , Semeins C M, Ajubi N E, Nijweide P J, Burger E H 1995 Pulsating fluid flow increases nitric oxide (NO) synthesis by osteocytes but not periosteal fibroblasts - correlation with prostaglandin upregulation. Biochemical and Biophysical Research Communications; 1995 Dec; 217(2) : $640-648$

[29]. Nomura S, Takano-Yamamoto T. Molecular events caused by mechanical stress in bone . Matrix Biology; 2000 May; $19(2)$ : 91 96

[30]. Kurata K, Heino T J , Higaki H, Vaananen H K. Bone marrow cell differentiation induced by mechanically damaged osteocytes in 3D gel embedded culture . Journal of Bone and Mineral Research; 2006 Apr; 21(4) : 616 - 625

[31]. Oshiro T, Shiotani A, Shibasaki Y, Sasaki T. Osteoclast induction in periodontal tissue during experimental movement of incisors in osteoprotegerin-defi cient mice. The Anatomical Record; 2002 Apr; 266(4) : $218-225$

[32]. Matsuda N, Morita N , Matsuda K, Watanabe M; Proliferation and differentiation of human osteoblastic cells associated with differential activation of MAP kinases in response to epidermal growth factor, hypoxia, and mechanical stress in vitro . Biochemical and Biophysical Research Communications; 1998 Aug; 249(2) : 350 - 354

[33]. Yang Y Q, Li X T, Rabie A B , Fu M K, Zhang D; Human periodontal ligament cells express osteoblastic phenotypes under intermittent force loading in vitro. Frontiers in Bioscience; $2006 \mathrm{Jan} ; 11$ : 776 - 781 
[34]. Nahm D S , Kim H J , Mah J , Baek S H; In vitro expression of matrix metalloproteinase-1, tissue inhibitor of metalloproteinase-1 and transforming growth factor-beta1 in human periodontal ligament fibroblasts . European Journal of Orthodontics; 2004 Apr; 26(2) : $129-135$

[35]. Yamaguchi M et al; Cathepsins B and L increased during response of periodontal ligament cells to mechanical stress in vitro . Connective Tissue Research; 2004; 45(3) : 181 - 189

[36]. Wallner BP, Mattaliano RJ, Hession C et al; Cloning and expression of human lipocortin, a phospholipase A2 inhibitor with potential anti-inflammatory activity. Nature. 1986 Mar 6-12;320(6057):77-81

[37]. Rhen T, Cidlowski JA; Anti-inflammatory action of glucocorticoids- new mechanisms for old drugs. N Engl J Med. 2005 Oct 20;353(16):1711-1723

[38]. Barnes P.J. Mediators of chronic obstructive pulmonary disease; Pharm. Rev. 2004;56:515-548

[39]. Barnes P.J., Chung K.F., Page C.P. Inflammatory mediators of asthma: an update; Pharmacol. Rev. 1998;50:515-596

[40]. Wu B., Li P., Liu Y., Lou Z., Ding Y., Shu C., Ye S., Bartlam M., Shen B., Rao Z. 3D structure of human FK506-binding protein 52: implications for the assembly of the glucocorticoid receptor/Hsp90/immunophilin heterocomplex. Proc. Natl. Acad. Sci. U.S.A. 2004;101:8348-8353

[41]. Dostert A., Heinzel T. Negative glucocorticoid receptor response elements and their role in glucocorticoid action. Curr. Pharm. Des. 2004;10:2807-2816

[42]. Ito K., Barnes P.J., Adcock I.M. Glucocorticoid receptor recruitment of histone deacetylase 2 inhibits IL-1b-induced histone H4 acetylation on lysines 8 and 12. Mol. Cell. Biol. 2000;20:6891-6903

[43]. Hall S.E., Lim S., Witherden I.R., Tetley T.D., Barnes P.J., Kamal A.M., Smith S.F. Lung type II cell and macrophage annexin I release: differential effects of two glucocorticoids. Am. J. Physiol. 1999;276:L114-L121.

[44]. Mittelstadt P.R., Ashwell J.D. Inhibition of AP-1 by the glucocorticoid-inducible protein GILZ. J. Biol. Chem. 2001;276:2960329610.

[45]. Anderson P., Phillips K., Stoecklin G., Kedersha N. Post-transcriptional regulation of proinflammatory proteins. J. Leukoc. Biol. 2004;76:42-47

[46]. Bergmann M., Barnes P.J., Newton R. Molecular regulation of granulocyte macrophage colony-stimulating factor in human lung epithelial cells by interleukin (IL)-1 $\beta$, IL-4, and IL-13 involves both transcriptional and post-transcriptional mechanisms. Am. J. Respir. Cell. Mol. Biol. 2000;22:582-589

[47]. Newton R., Seybold J., Kuitert L.M, Bergmann M., Barnes P.J; Repression of cyclooxygenase-2 and prostaglandin E2 release by dexamethasone occurs by transcriptional and post-transcriptional mechanisms Involving loss of polyadenylated mRNA. J. Biol. Chem. 1998b;273:32312-32321

[48]. Kalia S, Melsen B, Verna C. Tissue reaction to orthodontic tooth movement in acute and chronic corticosteroid treatment. Orthod Craniofac Res. 2004;7(1):26-34.

[49]. Yamane A, Fukui T, Chiba M. In vitro measurement of orthodontic tooth movement in rats given beta-aminopropionitrile or hydrocortisone using a time-lapse videotape recorder. Eur J Orthod. 1997;19(1):21-8.

[50]. Michael B. Ashcraft a, Karin A. Southard, Elizabeth A. Tolley ; The effect of corticosteroid-induced osteoporosis on orthodontic tooth movement; American Journal of Orthodontics and Dentofacial Orthopedics Volume 102, Issue 4, October 1992, Pages 310319

[51]. Verna C, Hartig LE, Kalia S, Melsen B; Influence of steroid drugs on orthodontically induced root resorption. Orthod Craniofac Res. 2006 Feb;9(1):57-62.

[52]. Gonzales C, Hotokezaka H, Matsuo K, Shibazaki T, Yozgatian JH, Darendeliler MA, Yoshida N; Effects of steroidal and nonsteroidal drugs on tooth movement and root resorption in the rat molar; Angle Orthod. 2009 Jul;79(4):715-26

[53]. Harraa S. Mohammed -Salih; Orthodontic tooth movement in low-dose for different courses methylprednisolone-treated rats; I.J.A.B.R., VOL. 2(3) 2012: 545-551

[54]. Abtahi M, Shafaee H, Saghravania N, Peel S, Giddon D, Sohrabi K; Effect of corticosteroids on orthodontic tooth movement in a rabbit model; J Clin Pediatr Dent. 2014 Spring;38(3):285-9. 